\title{
Issues concerning Landowner Management Plan Adoption Decisions: A Recursive Bivariate Probit Approach
}

\author{
Omkar Joshi, ${ }^{1}$ Donald L. Grebner, ${ }^{2}$ Ian A. Munn, ${ }^{2}$ and Robert K. Grala ${ }^{2}$ \\ ${ }^{1}$ Texas A\&M Forest Service, 200 Technology Way, College Station, TX 77845, USA \\ ${ }^{2}$ Department of Forestry, Mississippi State University, P.O. Box 9681, Thompson Hall, MS 39762-9681, USA \\ Correspondence should be addressed to Omkar Joshi; ojoshi@tfs.tamu.edu
}

Received 26 August 2014; Accepted 12 January 2015

Academic Editor: Piermaria Corona

Copyright (C) 2015 Omkar Joshi et al. This is an open access article distributed under the Creative Commons Attribution License, which permits unrestricted use, distribution, and reproduction in any medium, provided the original work is properly cited.

\begin{abstract}
Despite the likely benefits of having a written forest management plan, a small number of landowners in the United States have the one. A recursive bivariate probit model was used to identify the possible relationship between landowners' decision to obtain a management plan and their interest in future timber harvesting. Our study results based on recursive bivariate model suggest that landowners having larger land ownerships, longer forest ownership tenure, and higher education were more likely to have a forest management plan and future timber harvesting interest. While the landowners having interest for wildlife management were also interested to have a written management plan, they did not prefer to harvest in future. Study results indicate that written management plan means more than a timber harvesting strategy to landowners in general. Many elderly landowners with a low level of income and less formal education and those having small or medium sized tracts of forestland are less likely to own a written management plan. Therefore, this group requires special attention in various government sponsored forest management related extension activities. Future research on understanding landowner perception behind written management plan is recommended.
\end{abstract}

\section{Introduction}

Management plans are important technical documents which identify the planned forest management activities required to meet the objectives of forest landowners. A standard forest management plan provides information such as landowner management objectives, location and history of forestland, description and inventory of the existing resources, schedule of the course of activities, projection of expected benefits, and management recommendations for optimum benefits [1]. While the focus of such management plans in the past was mostly timber production and profit maximization, increasing public interest on ecosystem services, such as amenity, and recreation have warranted for more inclusive plans with emphasis on timber as well as nontimber services $[1,2]$.

Literature on private forest landowners indicates that presence of a written management plan is an indicator of their active involvement in forest management activities [37]. It has also been identified as a key attribute in landowner forest management decisions [3, 8-10]. Since thoughtful planning is an important prerequisite to achieve optimum benefits, private forest landowners who often do not follow management plan recommendations are likely to underachieve such benefits [5]. Owing to these insights, written management plan has become an eligibility criterion for measuring allocation of a land for timber use and other forest related tax benefits in the United States [7, 11]. State forestry agencies implement forest stewardship programs, authorized by cooperative Forestry Assistance Act of 1978, to encourage landowners to develop forest stewardship management plans [4]. Despite various efforts, 2004 national woodland owner survey indicates that only $3 \%$ of the landowners in the United States have obtained forest management plan [12]. While a substantial number of studies on landowners behavior have already examined landowners' decision-making with respect 
to timber or biomass harvesting, reforestation, amenity benefit, habitat management, and so forth [13-17], very limited empirical works have centered on landowner's decision to adopt management plan. Landowner decisions to obtain a forest management plan are, to the large extent, related to their plan to actively manage forestland. In particular, studies have shown that landowner decisions to adopt a forest management plan are related to the size of ownership, with owners of larger holding size more likely to adopt a written plan [18]. This makes intuitive sense considering the costs of obtaining a written management plan. Another related finding is that while many landowners harvest timberland during their forest ownership tenure, very few actually own a forest management plan $[12,19]$. For instance, Cleaves and Bennett [20] reported that $80 \%$ of landowners in western Oregon were positive about their future timber harvesting plans. Confirming this fact, Majumdar et al. [19] found that more than $89 \%$ of landowners having multiple-objectives to own timberland were involved in some form of timber harvesting during their forestland tenureship. However, only $32 \%$ of them had a written management plan. As earlier noted, results from 2004 national woodland owner survey were even more pessimistic in this connection.

Written management plan provides several benefits to landowners. For example, harvest scheduling, which estimates an appropriate time and acres of forestland to be harvested for optimal benefits, is an important component of a management plan [1]. An unplanned timber harvesting without a proper harvest scheduling would make forestland investment a less profitable avenue in the long-run. Similarly, many of these landowners may not be able to optimize benefits from new opportunities such as wood-based bioenergy, carbon sequestration, or forest certification program. One possible advantage of having a written management plan is that, apart from a general awareness, landowners would know more about both the potential benefits and conflicting implications, if any, of these programs on their primary forest management objectives. Despite the many potential benefits, passive to zero interest of the landowner in the preparation and implementation of the routine management activities, in part, question the effectiveness of stewardship programs, the need of management plans, and consequently the professional role of foresters in landowner forest management decisions.

Considering the exceptionally low adoption rate of management plan among landowners, it becomes important to investigate the factors that encourage or discourage landowners in adopting forest management plan. Understanding the factors that influence their management plan adoption decision can provide useful insights in extension and outreach programs aimed at enhancing landowners' capacity to meet their management objectives as well in sustaining forestlands. Following literature on related topics, landownership characteristics, ownership objectives, and sociodemographic attributes was considered as potential explanatory variables determining landowner interest in obtaining forest management plans. Additionally, given the likely relationship between landowner motivations for timber harvesting and their decision to obtain a management plan, we proposed to analyze these issues simultaneously.

\section{Method}

All the variables of interest were obtained from a survey of nonindustrial forest landowners in Mississippi. The state of Mississippi is in the heart of timber producing region of the United States with 19.79 million acres of total timberland [21]. The private forest landowners are the dominant ownership types in the state having more than three-fourth of total ownership [21]. The pine forest covers 6.62 million acres and mixed pine-hardwood forests cover 10.5 million acres. About $13.45 \%$ of total forestland is a regeneration forest in the state. The Mississippi Institute for Forest Inventory (MIFI) divides the total state into five districts (North, Delta, Central, Southeast, and Southwest) based on the differences associated with geography, physiography, and economic conditions among others [21]. Research suggests a lack of interest for getting a written management plan among private forest landowners in the region $[5,12]$. For example, Measells et al. [5] conducted a NIPF landowner survey in some southern states (Arkansas, Louisiana, Mississippi, and Tennessee) and found that $9.1 \%$ of surveyed landowners in Mississippi and $11 \%$ in the region had written management plans.

The survey instrument for this study, a detailed version of which can be found in Gruchy [22], was designed to reveal NIPF landowners' preferences in supplying woody biomass for wood-based bioenergy industries in Mississippi. From Mississippi property tax record database of NIPF landowners, twenty five hundred and sixty landowners having forest tract size of more than hundred acres were randomly selected for the survey. Following the usual recommendations given by Dillman [23], a mail survey was conducted in Mississippi from December 2009 to February 2010. Ownership characteristics, ratings of forest management objectives, and landowner sociodemographic information, obtained in the survey, were utilized in this study.

2.1. Model and Variable Definitions. As demonstrated by existing econometric research devoted to natural resource management $[3,13,24]$, we assume that landowner are utility maximizers. Hence, landowners would only show their interest in preparing management plan, if they maximize expected utility in doing so [25]. Economic rationality further dictates that landowners' decision to adopt a management plan is related with their plan to harvest in future. For instance, since forest management plan helps landowners to maximize their benefits, those having a plan to harvest are likely to be benefited by obtaining a forest management plan than others. To identify these relationships, two regression equation models, namely, landowner future plan to harvest model and forest management plan model, were considered. It was hypothesized that both regression equations might share some correlated disturbances particularly due to effect of some unobservable explanatory variables, similar to a seemingly unrelated regression model $[26,27]$. However, since both models had dichotomous dependent 
variables, seemingly unrelated regression approach could not be applied here directly. Therefore, its nonlinear equivalent called bivariate probit approach became appropriate for this study [26].

Given that many forest related activities correlate with each other, bivariate probit model has been routinely used in the forest economics literature. For example, Mozumder et al. (2008) [28] used bivariate probit model to investigate intended evacuation from wildfires in wild land-urban interface. Similarly, Creamer (2010) [29] used bivariate probit model to analyze family forest landowners' awareness of forest certification programs. Joshi et al. (2013) [30] also used the same model to understand woody biomass harvesting behavior in Mississippi. Additionally, as plan to harvest in future could be endogenous to landowner decision to adopt a management plan, we jointly estimated the following relationship by recursive bivariate probit model approach $[26,27]$ :

$$
\begin{gathered}
y_{1 i}^{*}=\beta_{1 i} x_{1 i}+\mu_{1 i} \\
{\left[y_{1 i}=1 \text { if } y_{1 i}^{*}>0,0 \text { otherwise }\right]} \\
y_{2 i}^{*}=\beta_{2 i} x_{2 i}+\gamma y_{1 i}+\mu_{2 i} \\
{\left[y_{2 i}=1 \text { if } y_{2 i}^{*}>0,0 \text { otherwise }\right],}
\end{gathered}
$$

where $y_{1 i}^{*}$ and $y_{2 i}^{*}$ are two latent dependent variables and $y_{1 i}$ and $y_{2 i}$ represent their observable components in the model. Similarly, $x_{1 i}$ and $x_{2 i}$ represent the set of factors affecting landowner plan to harvest and future and their decision to obtain a management plan, $\beta_{1 i}$ and $\beta_{2 i}$ represent vector of parameter coefficients, and $\mu_{1 i}$ and $\mu_{2 i}$ are error terms, respectively $[26,27]$.

The bivariate normal cumulative distribution function density can be expressed as

$$
\Phi\left(x_{1 i}, x_{2 i}, \rho\right)=\frac{e^{-(1 / 2)\left(x_{1 i}^{2}+x_{2 i}^{2}-2 \rho x_{1 i} x_{2 i}\right) /\left(1-\rho^{2}\right)}}{2 \pi\left(1-\rho^{2}\right)^{1 / 2}} .
$$

The likelihood function can be expressed as

$$
\ln L=\sum_{i=1}^{n} \ln \Phi\left(w_{i 1}, w_{i 2}, \rho_{i *}\right)
$$

The correlation among unobserved explanatory variables in both equations can be determined by the correlation coefficient $(\rho)$, significance of which is an indication of correlated disturbance terms. Finally, a nonlinear conditional mean function, for estimating marginal effects in this model, can be obtained as

$$
E\left[Y_{1 i} \mid Y_{2 i}, x_{i}\right]=\frac{\Phi\left(\gamma x_{i},\left(2 Y_{2 i}-1\right) \gamma x_{i},\left(2 Y_{2 i}-1\right) \rho\right)}{\Phi\left[\left(2 Y_{2 i}-1\right) \gamma x_{i}\right]}
$$

As explained earlier, two regression equations were proposed for econometric analysis. In first regression model, dependent variable MGTDECI was binary, with a "1" indicating those respondents who had a written management plan and a "0" otherwise. For second regression model, dependent variable FUHAR was also a binary, with a "1" for respondents who planned to harvest in future and a " 0 " otherwise. All the variables considered for econometric analysis are defined in Table 1 with relevant descriptive statistics.

Among independent variables, size of forestland (ACRE), one measure of landowner ownership characteristics, was a categorical variable. Existing literature indicated that landowners having higher forest acres were more interested in harvesting than others [13, 31]. Zhang and Mehmood [32] reported that landowners having more than 500 acres were significantly more interested in seeking technical assistance from professional foresters than others. Consistent with these findings, Liao and Zhang [33] concluded that NIPF landowners, particularly those having more than 500 acres, were likely to maximize profit rather than utility from their forestland. Therefore, following Zhang and Mehmood [32], the binary variable "ACRE" was assigned as a " 1 " for those having forestland of more than 500 acres and " 0 " otherwise. The sign of this variable was expected to be positive in both regression models. Another ownership characteristic was landowner duration of ownership (DUR) which was measured on a continuous scale. As timber harvesting is a source of income, landowners who spend time and effort in forest management would prefer a return from it in future. Similarly, since landowners having longer ownership tenure are also likely to understand the importance of a written management plan, we expected a positive relationship of this variable to exist with both dependent variables. Existing literature on technical assistance indicated that landowners with a pine plantation in their forestland were interested in seeking technical assistance for harvesting and reforestation [32]. Joshi and Mehmood [13] also reported an active forest management interest amongst southern landowners who planted pine in their forestland. Following Zhang and Mehmood [32], this variable was assigned as "1" if landowners had more than $50 \%$ of pine plantation in forestland and " 0 " otherwise. This variable was expected to have a positive association with both dependent variables.

Among attributes explaining landowner management motivations, landowner bequest motivation (BEQUEST), which was assigned as a "1" for landowners having interest in passing forestland to their heirs and " 0 " for others, has been identified as one of the most important forest management objectives in the southern United States [5]. Since the bequest motive generally is a passive approach to managing forestland, we expected a negative association of this management motivation to exist with a landowner decision to adopt a forest management plan and their plan to harvest timber. Another variable characterizing ownership motivation was landowner interest in wildlife habitat management (HAB). Since a written management plan can help landowners to take the best nontimber related course of action to meet the wildlife habitat management goal, we expected a positive sign of this attribute with management plan regression model. However, landowners who prefer to manage forestland for wildlife habitat would not plan to harvest timber. Therefore, we expected its negative sign in future plan to harvest regression model. Two other variables capturing ownership motivations were maintaining forestland as an investment 
TABLE 1: Definition and descriptive statistics of variables used in the model for landowner decision to prepare forest management plan.

\begin{tabular}{|c|c|c|c|}
\hline Variable & Definition units & Mean & Std. dev. \\
\hline MGTDECI & $\begin{array}{l}\text { Whether or not landowner obtained a forest management plan, } 1 \text { if obtained, } 0 \\
\text { otherwise }\end{array}$ & 0.279 & \\
\hline ACRE & Total land of the landowner, 1 if it is more than 500 acres, 0 otherwise & 0.244 & \\
\hline PP & The land occupied by planted pine, 1 if more than $50 \%, 0$ otherwise & 0.454 & \\
\hline BEQUEST & Landowner interest for timberland bequest, 1 if landowner is interested, 0 otherwise & 0.886 & \\
\hline FUHAR & Landowner plan to harvest timber in future, 1 if landowner is interested, 0 otherwise & 0.911 & \\
\hline HAB & $\begin{array}{l}\text { Wildlife habitat management objective, } 1 \text { if management objective is wildlife habitat } \\
\text { management, } 0 \text { otherwise }\end{array}$ & 0.796 & \\
\hline FIN & $\begin{array}{l}\text { Obtaining optimal financial benefit as management objective, } 1 \text { if management } \\
\text { objective is obtaining financial benefit, } 0 \text { otherwise }\end{array}$ & 0.83 & \\
\hline INV & Considering forest as an investment asset, 1 if landowner considers, 0 otherwise & 0.84 & \\
\hline DUR & Duration of timberland ownership in years & 33.219 & 23.15 \\
\hline AGE & The age of the landowner & 64.72 & 12.65 \\
\hline EDUCATION & $\begin{array}{l}\text { The highest level of landowner's education, } 1 \text { if respondent has bachelor's degree or } \\
\text { higher, } 0 \text { otherwise }\end{array}$ & 0.574 & \\
\hline GENDER & Gender of landowner, 1 if male, 0 otherwise & 0.820 & \\
\hline INCOME & $\begin{array}{l}\text { Income of landowner, } 1 \text { if annual household income is more than } \$ 50,000,0 \\
\text { otherwise }\end{array}$ & 0.756 & \\
\hline
\end{tabular}

${ }^{*}$ Standard deviation is only reported for a continuous variable.

of assets (INV) and expecting highest financial return from forestland (FIN). As landowners having such management motivations would prefer to plant loblolly pine Dipesh et al. [34] optimize economic benefits from their forestland, we expected positive relationship of these attributes with both dependent variables.

Among sociodemographic variables, INCOME, measured on categorical scale, was expressed as a "1" for landowners having annual family income of 50,000 and above and "0" for all others. Since landowners with a high annual income would like to actively manage their forestland, it was expected to have a positive relationship with both dependent variables. Similarly, the attribute EDUCATION, which was categorical in nature, was expressed as a " 1 " for landowners having at least a bachelor's degree and " 0 ” for all others. As we know, education helps to enhance overall professional and managerial skills. Therefore, more formally educated landowners, who have been found to participate actively in biomass harvesting and silvicultural and other property management activities [3, 13], might realize the benefits of having a forest management plan more than others. Therefore, we expected a positive association for this variable with landowner decision to prepare a forest management plan as well as their interest in timber harvesting. The attribute gender (GENDER), which was assigned as a " 1 " for male landowners and as a " 0 " for others, was also included in the model. Bliss et al. (1997) [35] reported that female landowners were less interested in management activities such as prescribed burning and herbicide use than their male counterparts in Mid-Southern United States. On the other hand, female landowners in Alabama were more interested to seek technical assistance than male landowners [10]. Given these results, we were not sure whether there would be more or less likelihood of female landowners, in comparison to male, in terms of obtaining a forest management plan and interest in timber harvesting. Finally, the landowners age (AGE), which was measured in continuous scale, was expected to have negative coefficient with both dependent variables. This is because older landowners, all else constant, would be less interested in active forest management activities [3].

\section{Result}

Out of 2,438 successful mailings, 703 landowners responded to the mail survey, thereby representing a response rate of $28.8 \%$. For this study, however, only 451 respondents completely answered all the questions of interest. Average tract size of our study population was 461.8 acres. The majority of the respondents were elderly with an average age of about 65 years, and most (87\%) had previously harvested timber and were planning to harvest in future (91\%). However, only about $28 \%$ of the respondents had a written management plan. Highest percentage of the respondent landowners had a bachelor's degree, followed by a high school degree. Consistent with the general landowner characteristics, their median income (around $\$ 87,000$ ) was well above than average income in the state. To account for nonresponse bias, sociodemographic attributes of the landowner such as age, acreage, and income between early and late respondents were compared. These attributes, between early and late respondents, were found to be statistically insignificant. Similarly, 50 randomly selected nonrespondents were asked why they did not fill out our survey questionnaire. The noted reasons for their nonresponses reflected ownership changes, lack of time, and lack of interest for filling out any survey questions. Respondents and nonrespondents groups were generally 
TABLE 2: Results of recursive bivariate probit regression on landowner decision to prepare forest management plan and to harvest timber in future.

\begin{tabular}{|c|c|c|c|c|}
\hline \multirow{2}{*}{ Variables } & \multicolumn{2}{|c|}{ Management plan model } & \multicolumn{2}{|c|}{ Future harvest model } \\
\hline & Coefficients ( $z$-ratio) & Marginal effects & Coefficients ( $z$-ratio) & Marginal effects \\
\hline ACRES & $0.302^{* *}(1.98)$ & 0.117 & $0.704^{*}(1.87)$ & 0.008 \\
\hline BEQUEST & $-0.193(0.88)$ & -0.077 & & \\
\hline FUHAR & $1.70^{* * *}(5.45)$ & 0.433 & & \\
\hline $\mathrm{HAB}$ & $0.323^{*}(1.88)$ & 0.125 & $-0.88^{* * *}(-3.00)$ & -0.001 \\
\hline FIN & $-0.279(1.27)$ & -0.111 & $0.85^{* * *}(3.12)$ & 0.013 \\
\hline INV & & & $0.664^{* *}(2.41)$ & 0.007 \\
\hline DUR & $0.006^{*}(2.13)$ & 0.002 & $0.001(0.31)$ & 0.0006 \\
\hline $\mathrm{PP}$ & & & $0.746^{* * *}(3.46)$ & 0.009 \\
\hline GENDER & $-0.261(1.62)$ & -0.103 & & \\
\hline INCOME & $0.466^{* * *}(2.66)$ & 0.176 & $-0.248(-1.08)$ & -0.0006 \\
\hline AGE & & & $-0.016^{*}(1.83)$ & -0.006 \\
\hline EDUCATION & $0.176(1.20)$ & 0.069 & $0.640^{* * *}(2.77)$ & 0.006 \\
\hline INTERCEPT & $-2.50^{* * *}(-0.358)$ & & $1.55^{* *}(2.29)$ & \\
\hline Log-likelihood ratio & -341.475 & & & \\
\hline Rho & $-0.78^{* * *}(6.78)$ & & & \\
\hline
\end{tabular}

similar in terms of their sociodemographic attributes. Slightly different observations found in followup phone call was with education attribute, as more nonrespondents were less formally educated than respondent landowners. These reasons reflect personal preferences or issues behind nonresponses rather than anything causing systematic bias. Nonetheless, a nonresponse bias cannot be neglected completely in case of a low response rate and results require a careful interpretation. Results from the recursive bivariate probit model explaining the potential determinants of NIPF landowner decisions to prepare a forest management plan and their future plan to harvest timber are reported in Table 2. Similar to what we expected, the correlation coefficient $(\rho)$ was significant, indicating that both regression equations shared correlated disturbances and would suffer from specification bias, should we opted to analyze them independently. The log likelihood ratio was significant at $1 \%$ indicating that the recursive bivariate regression model was overall a good fit. None of the explanatory variables used in the model suffered from multicollinearity. Some of the independent variables with inconsequential explanatory power were dropped from both models, after making a confirmation with a likelihood ratio test.

3.1. Results from Management Plan Regression Model. Among the nine variables included in the final management plan regression model, five variables were significant at the $10 \%$ level or less. Among the variables characterizing landownership, size of landowner's forestland had a positive coefficient and was significant at the $1 \%$ level. In terms of marginal effects, landowners with a large tract of forestland were $11 \%$ more likely to prepare a forest management plan than those having a small or medium tract of forest. Similarly, landowner duration of ownership was also positive and significant at the 5\% level. Among the variables that characterize landowner management motivations, landowners who plan to harvest timber in the future were positive and significantly contributing dependent variable of interest. Estimated marginal effects revealed that landowners with a plan to harvest timberland in the future were $43 \%$ more likely to obtain a management plan than those who do not wish to harvest timberland in the future. As expected, wildlife management (HAB) was positive and significant at $10 \%$ level. Among the sociodemographic variables, annual income had a positive and significant impact on a landowner's decision to obtain a forest management plan.

3.2. Results from Future Plan to Harvest Regression Model. Among the nine variables included in the final future plan to harvest regression model, six variables were significant at the $10 \%$ level or less. Among the variables characterizing landownership, size of landowner's forestland had a positive coefficient and was significant at the $10 \%$ level. Among forest management objectives, receiving the highest financial return possible from forestland (FIN) was positive and significant at $1 \%$ level. Likewise, as expected, wildlife management (HAB) was negative and significant at 5\% level. Similarly, landowner interest on maintaining forestland as an investment of assets (INV) was also significant at 5\% level. Among ownership characteristics, pine plantation (PP) was positive and significant at $1 \%$ level. Finally, among the sociodemographic variables, landowner education (EDU) was positive and significant at $1 \%$ level, whereas age (AGE) was negative and significant at $10 \%$ level. 


\section{Discussion}

Consistent with our expectations, results indicated that landowners having a larger tract of forestland, holding all else equal, were more likely to obtain a forest management plan. Similar to earlier conclusions [31,36], landowners with large ownerships may perceive their property as an investment and would like to optimize the potential financial benefits. Past results indicated that the higher income group of landowners, who are likely to have greater access to resources needed for management, can consider forestland as an investment and would be interested in optimizing financial benefits $[3,30]$. Results based on second model generally complemented above findings as landowners having higher acres of forestland, seeking highest financial return, having pine plantations, and considering forestland as an investment opportunity were planning to harvest in the future. However, significance level and marginal effects of the attributes such as acres and income were stronger in the management plan regression model indicating that management plan strongly appeals to wealthier landowners having higher landholding size. These results indicate that landowners having smaller landholding size might consider management plan as a financial burden as their net benefits would be relatively smaller compared to those having higher land acreage.

Landowners with a plan for timber harvesting in the future can be argued as active forest managers. Since a forest management plan provides a detailed schedule of activities to be carried out to meet landowner objectives, the interest of these landowners in forest management plans, all else equal, seems justifiable. Similarly, result indicated that landowners would more likely prepare a forest management plan if the duration of their land tenure was longer. Since people learn from experience, it is fair to argue that people would learn, either by themselves or through government sponsored extension programs, about best suited alternatives for them during the course of time.

One interesting finding was that while landowners having wildlife habitat management objectives were more interested in obtaining a management plan, they were significantly less interested in future timber harvesting activities than others. These results indicate that management plan does not only appeal to those having timber harvesting objectives but also to others with an active interest in forest management activities. As ideal wildlife habitat management requires identification of habitat component, wildlife inventory, and potential management practices [37], thoughtful planning is needed to meet the management goal. This could be the reason why landowner having wildlife management objectives refrained to harvest timberland but were interested in obtaining a management plan.

Our results suggest that landowners having low income and less formal education were not as interested in preparing forest management plans and in timber harvesting. Moreover, elderly landowners were less interested in future timber harvesting. Our study results indicate that such landowners do not consider forest management as an investment opportunity and prefer to manage forestland passively. This general finding is consistent with other landowner studies in the past [19, 38, 39]. Majumdar et al. [19] noted that only $10 \%$ of the landowners with lower income and education had a written management plan. Despite the income generation opportunities, recent literature $[19,38,40]$ indicated that elderly landowners with small tract size, with a lower income and with a lower level of education, do not consider the forest as a potential source of income.

\section{Conclusion}

This study has highlighted some important issues related to private forest landowners' likelihood in preparing forest management plans. Since a large percentage of landowners in the United States have a small or medium size of forest tract, which are rapidly declining due to parcelization [41, 42], the reason behind the low motivation for a management plan among the majority of the NIPF landowners is evident. As a large tract of forestland provides higher productivity and economic viability, a decrease in landholding size, coupled with an increase in landownership number, has resulted in passive or even lack of interest amongst landowners in forest management activities [18, 42]. Therefore, our results point to a need for awareness and training for elderly, less formally educated, and underserved group of landowners pertaining to the potential benefits of having a management plan. While some elements of forest management plan might be common among landowners, it is always important to obtain an individual written forest management plan from a professional forester to meet individual forest management goals. Management plan provides several economic, environmental, and tax related benefits. While there might be some initial costs to prepare, landowners in local income categories can generally benefit from federally assisted stewardship programs in obtaining a written management plan.

Despite the importance of a management plan in sustainable forest management, not many studies in the past have seriously analyzed this issue. We admit the fact that, in the absence of well documented literature, the selection of independent variables may have suffered from researcher subjectivity bias. Nevertheless, it is clear from our study that many landowners with a low level of income and education and those having small or medium tract size of forestland, who are interested in active forest management but are not aware of forest management plan, need special attention in government sponsored extension efforts to increase their motivation to prepare forest management plans in United States.

\section{Conflict of Interests}

The authors declare that there is no conflict of interests regarding the publication of this paper.

\section{References}

[1] P. Bettinger, K. Boston, J. P. Siry, and D. L. Grebner, Forest Management and Planning, Academic Press, Burlington, Mass, USA, 2010. 
[2] L. Diaz-Balteiro and C. Romero, "Sustainability of forest management plans: a discrete goal programming approach," Journal of Environmental Management, vol. 71, no. 4, pp. 351-359, 2004.

[3] S. Joshi and K. G. Arano, "Determinants of private forest management decisions: a study on West Virginia NIPF landowners," Forest Policy and Economics, vol. 11, no. 2, pp. 118-125, 2009.

[4] USFS, Forest Stewardship Program: National Standards and Guidelines, SDA Forest Service, State and Private Forestry Cooperative Forestry, Washington, DC, USA, 2009.

[5] M. K. Measells, S. C. Grado, H. G. Hughes, M. A. Dunn, J. Idassi, and B. Zielinske, "Nonindustrial private forest landowner characteristics and use of Forestry services in Four Southern States: results from a 2002-2003 mail survey," Southern Journal of Applied Forestry, vol. 29, no. 4, pp. 194-199, 2005.

[6] A. L. Ross-Davis, S. R. Broussard, D. F. Jacobs, and A. S. Davis, "Afforestation motivations of private landowners: an examination of hardwood tree plantings in Indiana," Northern Journal of Applied Forestry, vol. 22, no. 3, pp. 149-153, 2005.

[7] Texas Comptroller Office, Manual for the Appraisal of Timberland, Texas Comptroller of Public accounts, Austin, Tex, USA, 2004.

[8] S. Størdal, G. Lien, and S. Baardsen, "Analyzing determinants of forest owners' decision-making using a sample selection framework," Journal of Forest Economics, vol. 14, no. 3, pp. 159176, 2008.

[9] G. Wicker, "Motivation for private forest landowners," in Southern Forest Resource Assessment, D. Wear and J. Greis, Eds., p. 635, USDA Forest Service Southern Research Station, 2002.

[10] J. Gan and E. Kebede, "Multivariate probit modeling of decisions on timber harvesting and request for assistance by African-American forestland owners," Southern Journal of Applied Forestry, vol. 29, no. 3, pp. 135-142, 2005.

[11] M. Megalos and R. Hamilton, Your Forest Management Plan: A Guide for North Carolina Landowners, College of Agriculture and Life Sciences, NC State University, Raleigh, NC, USA, 2012.

[12] B. J. Butler, E. C. Leatherberry, C. Best, M. A. Kilgore, R. N. Sampson, and K. Larson, "America's family forest owners," Journal of Forestry, vol. 102, no. 7, pp. 4-14, 2004.

[13] O. Joshi and S. R. Mehmood, "Factors affecting nonindustrial private forest landowners' willingness to supply woody biomass for bioenergy," Biomass and Bioenergy, vol. 35, no. 1, pp. 186-192, 2011.

[14] N. C. Poudyal and D. G. Hodges, "Factors influencing landowner interest in managing wildlife and avian habitat on private forestland," Human Dimensions of Wildlife, vol. 14, no. 4, pp. 240-250, 2009.

[15] R. H. Beach, S. K. Pattanayak, J.-C. Yang, B. C. Murray, and R. C. Abt, "Econometric studies of non-industrial private forest management: a review and synthesis," Forest Policy and Economics, vol. 7, no. 3, pp. 261-281, 2005.

[16] G. S. Amacher, M. C. Conway, and J. Sullivan, "Econometric analyses of nonindustrial forest landowners: Is there anything left to study?" Journal of Forest Economics, vol. 9, no. 2, pp. 137164, 2003.

[17] J. Kuuluvainen, H. Karppinen, and V. Ovaskainen, "Landowner objectives and nonindustrial private timber supply," Forest Science, vol. 42, no. 3, pp. 300-309, 1996.

[18] J. Romm, R. Tuazon, and C. Washburn, "Relating forestry investment to the characteristics of nonindustrial private forestland owners in northern California," Forest Science, vol. 33, no. 1, pp. 197-209, 1987.
[19] I. Majumdar, L. Teeter, and B. Butler, "Characterizing family forest owners: a cluster analysis approach," Forest Science, vol. 54, no. 2, pp. 176-184, 2008.

[20] D. A. Cleaves and M. Bennett, "Timber harvesting by nonindustrial private forest landowners in Western Oregon," Western Journal of Applied Forestry, vol. 10, no. 2, pp. 66-71, 1995.

[21] S. R. Gruchy, An assessment of nonindustrial private forest landowner willingness to harvest biomass in support of bioenergy production in Mississippi [M.S. thesis], Mississippi state University, Starkville, Miss, USA, 2011.

[22] MFC, Forest Inventory Southwest Region, Mississippi, Mississippi Institute for Forest Inventory, Mississippi Forestry Commission, 2014.

[23] D. A. Dillman, Mail and Internet Surveys: The Tailored Design Method, John Wiley \& Sons, New York, NY, USA, 2nd edition, 2000.

[24] A. Hussain, I. A. Munn, D. Hudson, and B. West, "Attributebased analysis of hunters' lease preferences," Journal of Environmental Management, vol. 91, no. 12, pp. 2565-2571, 2010.

[25] C. F. Manski, "The structure of random utility models," Theory and Decision, vol. 8, no. 3, pp. 229-254, 1977.

[26] C. Monfardini and R. Radice, "Practitioners' corner: testing exogeneity in the bivariate probit model: a Monte Carlo study," Oxford Bulletin of Economics and Statistics, vol. 70, no. 2, pp. 271-282, 2008.

[27] W. H. Greene, Econometric Analysis, Prentice-Hall International, Englewood Cliffs, NJ, USA, 6th edition, 2008.

[28] P. Mozumder, N. Raheem, J. Talberth, and R. P. Berrens, "Investigating intended evacuation from wildfires in the wildlandurban interface: application of a bivariate probit model," Forest Policy and Economics, vol. 10, no. 6, pp. 415-423, 2008.

[29] S. F. Creamer, Econometric analysis of family forest owners' forest certification program participation behavior and optimal harvesting decision under uncertainty [Ph.D. dissertation], Washington State University, 2010.

[30] O. Joshi, D. L. Grebner, A. Hussain, and S. C. Grado, "Landowner knowledge and willingness to supply woody biomass for wood-based bioenergy: sample selection approach," Journal of Forest Economics, vol. 19, no. 2, pp. 97-109, 2013.

[31] G. K. Arano, I. A. Munn, J. Gunter, and S. Bullard, "Modeling landowners' participation in a proposed reforestation loan program," Small-Scale Forest Economics, Management and Policy, vol. 3, no. 2, pp. 177-190, 2004.

[32] D. Zhang and S. R. Mehmood, "Predicting nonindustrial private forest landowners' choices of a forester for harvesting and tree planting assistance in Alabama," Southern Journal of Applied Forestry, vol. 25, no. 3, pp. 101-107, 2001.

[33] X. Liao and Y. Zhang, "An econometric analysis of softwood production in the U.S. South: a comparison of industrial and nonindustrial forest ownerships," Forest Products Journal, vol. 58, no. 11, Article ID 10365, pp. 69-74, 2008.

[34] K. C. Dipesh, R. E. Will, T. B. Lynch, R. Heinemann, and R. Holeman, "Comparison of loblolly, shortleaf, and pitch X loblolly pine plantations growing in Oklahoma," Forest Science, 2014.

[35] J. C. Bliss, S. K. Nepal, R. T. Brooks Jr., and M. D. Larsen, "In the mainstream: environmental attitudes of mid-south forest owners," Southern Journal of Applied Forestry, vol. 21, no. 1, pp. 37-43, 1997.

[36] V. Nagubadi, K. T. McNamara, W. L. Hoover, and W. L. Mills, "Program participation behavior of nonindustrial forest 
landowners: a probit analysis," Journal of Agricultural and Applied Economics, vol. 28, no. 2, pp. 323-336, 1996.

[37] G. Yarrow, "Developing a wildlife management plan," Extension forestry and natural resources, Clemson Cooperative Extension, 2009, http://www.clemson.edu/extension/natural resources/wildlife/publications/fs1_developing_wildlife_management_plan.html.

[38] O. Joshi and S. R. Mehmood, "Segmenting southern nonindustrial private forest landowners on the basis of their management objectives and motivations for wood-based bioenergy," Southern Journal of Applied Forestry, vol. 35, no. 2, pp. 87-92, 2011.

[39] R. A. Kluender and T. L. Walkingstick, "Rethinking how nonindustrial landowners view their lands," Southern Journal of Applied Forestry, vol. 24, no. 3, pp. 150-158, 2000.

[40] G. Hughes, M. K. Measells, S. C. Grado, M. A. Dunn, J. O. Idassi, and R. J. Zielinske, "Underserved forest landowner workshops: opportunities for landowners and extension," Journal of Extension, vol. 43, no. 4, article 4FEA5, 2005.

[41] D. R. Becker, K. Skog, A. Hellman, K. E. Halvorsen, and T. Mace, "An outlook for sustainable forest bioenergy production in the Lake States," Energy Policy, vol. 37, no. 12, pp. 5687-5693, 2009.

[42] S. R. Mehmood and D. Zhang, "Forest parcelization in the United States: a study of contributing factors," Journal of Forestry, vol. 99, no. 4, pp. 30-34, 2001. 

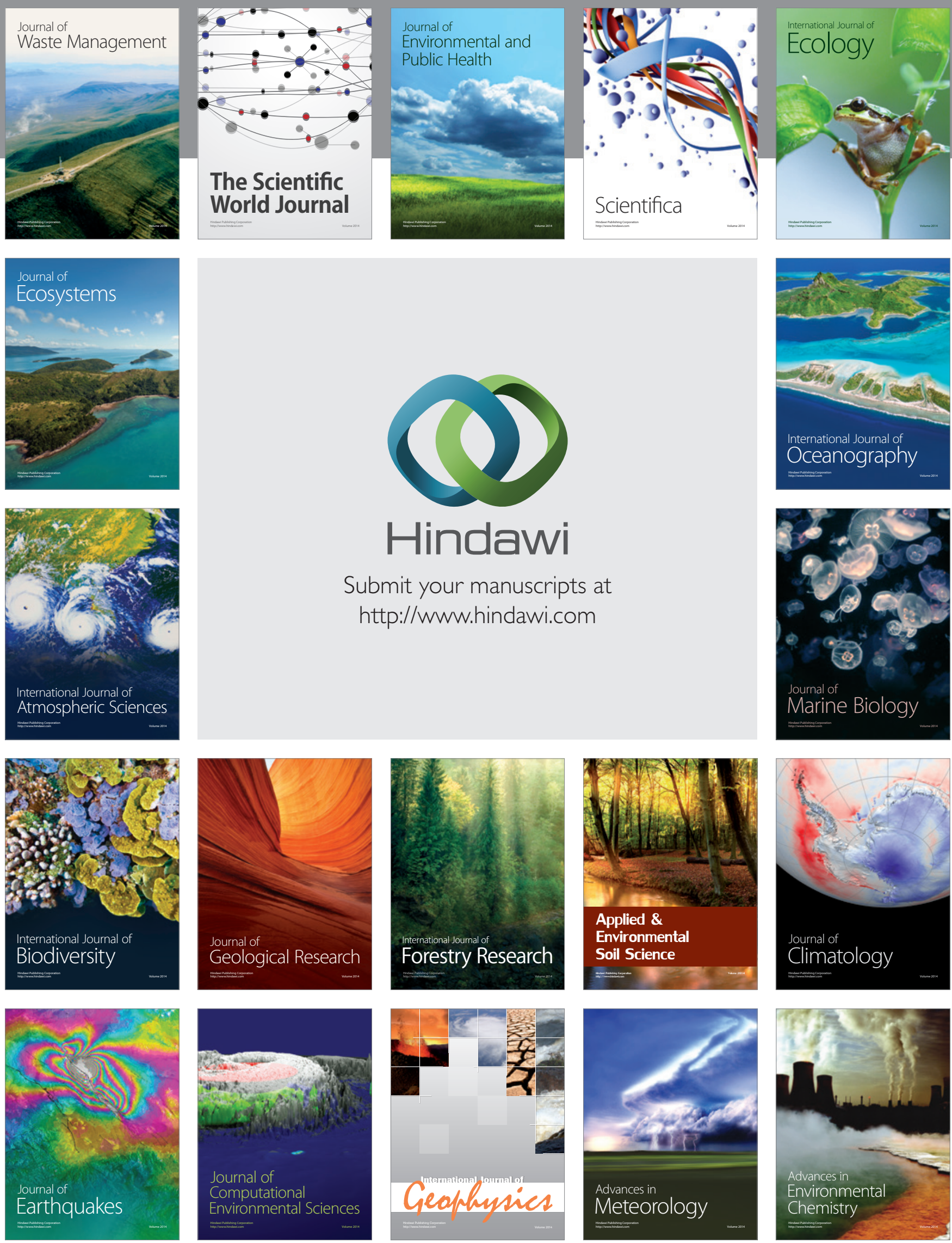